\title{
Vibrational Spectral Analysis (Ft-Ir And Ft-Raman) Andnlo, Homo Lumo And Mep Analysis Of 4, 4 Isopropylidenebis 2,6 Dichlorophenol
}

\author{
S. Saravanan ${ }^{1}$, G. Kanagan ${ }^{2}$, G. Satheeshkumar ${ }^{3}$, S.Pari ${ }^{4}$, R. Sambasivam ${ }^{5}$ \\ ${ }^{1,2,3,4}$ Department of Physics, National College (Autonomous), Triuchirappalli -620 001 \\ ${ }^{5}$ Department of Physics, Urumu Dhanalakshmi College, Triuchirappalli-620 019
}

Available online at: www.isroset.org

Received: 08/May/2019, Accepted: 09/Jun/2019, Online: 30/Jun/2019

\begin{abstract}
The experimental and theoretical study on the structures and vibrations of 4,4-ISOPROPYLIDENE BIS 2,6DICHLOROPHENOL (abbreviated as 4IBD) are presented. The FT-IR and FT-Raman spectra of the title compound have been recorded in the region $4000-400 \mathrm{~cm}^{-1}$ and $3500-100 \mathrm{~cm}^{-1}$ respectively. The molecular structures, vibrational wavenumbers, infrared intensities and Raman activities were calculated using DFT (B3LYP) method with 6-31+G (d) basis set. The most stable conformer of 4IBD) is identified from the computational results. HOMO and LUMO energies were determined by timedependent TD-DFT approach. Molecular electrostatic potential map also analysis by this present compound, respectively.
\end{abstract}

Keywords- 4, 4-ISOPROPYLIDENE BIS 2,6-DICHLOROPHENOL, Mulliken analysis, FT-IR,FT-Raman, HOMO and LUMO,extra

\section{INTRODUCTION}

The electro negative atom such as halogen attached to the (dichirophenal) phenol in a highly reactive the dichirophenal. The 4, 4'-isopropylitenepis (2,6-dichirophenol) phenal is a white crystalline powder with molecular formula $\left(\mathrm{C}_{15} \mathrm{H}_{12} \mathrm{Cl}_{4} \mathrm{O}_{2}\right)$. The vibration spectroscopic using DFT methods have reported on methyl phenol. Therefore the present investigation was undertaken study the vibration of FT-IR, FT-Raman spectra of the molecule completely and to identify the vibrations normal modes with grater wave number accuracy. Predication of vibration frequency of polyatomic molecules by quantum chemical calculation has become very popular because of accurate and consistent description of the experimental data. $4 \mathrm{pmp}$ was investigated by using B3LYP calculation with 6-31+G (d) and 6-311++G (d, p) basis sets.

\section{EXPERIMENTAL DETAILS}

The sample IPDP in the solid form was provided by the Lancaster Chemical Company (UK) with a purity of greater than $98 \%$ and it was used as such without further purification. The FT-Raman spectrum of IPDP was recorded using $1064 \mathrm{~nm}$ line of Nd:YAG laser as excitation wavelength in the region $3500-100 \mathrm{~cm}^{-1}$ on a Thermo Electron Corporation model Nexus 670 spectrometer equipped with FT-Raman module accessory. The FT-IR spectrum of IPDP was recorded in the frequency region $4000-400 \mathrm{~cm}^{-1}$ on a Nexus 670 spectrometer equipped with an MCT detector, a $\mathrm{KBr}$ pellet technique.

\section{COMPUTATIONAL DETAILS}

The molecular geometry optimization and vibrational frequency calculations were carried out for,IPDP with GAUSSIAN 09W [1] package the density functional theory used in B3LYP i.e. Becke's three-parameter hybrid functional with the Lee-YangParr correlation functional methods $[2,3]$ with $6-31+\mathrm{G}(\mathrm{d})$ and $6-311++\mathrm{G}(\mathrm{d}, \mathrm{p})$ basis sets. Scaling of the force field was performed according to the scaled quantum mechanical (SQM) procedure [4]. The calculated potential energy distribution (PED) and predicted IR and Raman intensities were done on a PC with the Version V7.0 of the MOLVIB program written by Sundius [5,6]. To achieve a close agreement between observed and calculated frequencies, the least-square fit refinement algorithm was used. By combining the results of the GUASSVIEW [7] program with symmetry considerations, along with the available related molecules, vibrational frequency assignments were made with a high degree of accuracy.

\section{PREDICTION OF RAMAN INTENSITY}


The Raman activities $\left(S_{R}\right)$ calculated with the Gaussian 09W Program were converted to Raman intensities $\left(I_{R}\right)$ using the following relationship derived from the intensity theory of Raman scattering [8-9].

$$
I_{R}=\frac{f\left(v_{0}-v_{i}\right)^{4} S_{R}}{v_{i}\left[1-\exp \left(-h c v_{i} / k T\right)\right]}
$$

where $v_{0}$ is the laser exciting frequency in $\mathrm{cm}^{-1}$ (in this work, we have used the excitation wavenumber $v_{0}=9392.4 \mathrm{~cm}^{-1}$, which corresponds to the wavelength of $1064 \mathrm{~nm}$ of a Nd:YAG laser), $v_{i}$ is the vibrational wavenumber of the ith normal mode (in $\mathrm{cm}^{-1}$ ) and $S_{R}$ is the Raman scattering activity of the normal mode $v_{\mathrm{i}}, f$ (is the constant equal to $10^{-12}$ ) is a suitably chosen common normalization factor for all peak intensities. $h, k, c$, and $T$ are Planck constant, Boltzmann constant, speed of light, and temperature in Kelvin, respectively.

\section{POLARIZABILITY AND HYPERPOLARIZABILITY}

The polarizability $(\alpha)$ and the first-order hyperpolarizability $\left(\beta_{0}\right)$ of this novel molecular system and the electric dipole moment $(\mu)$ of the IPDP were calculated using B3LYP method with $6-31+\mathrm{G}(\mathrm{d})$ and $6-311++\mathrm{G}(\mathrm{d}, \mathrm{p})$ basis sets, based on the finite field approach. In presence of an applied electric field, the energy of a system is a function of the electric field. Polarizability and hyperpolarizability characterize the response of a system in an applied electric field [10]. The first hyperpolarizability is a third-rank tensor that can be described by a $3 \times 3 \times 3$ matrix. The 27 components of the $3 \mathrm{D}$ matrix can be reduced to 10 components due to the Kleinman symmetry [11]. The components of $\beta_{0}$ are defined as the coefficients in the Taylor series exponents the energy in the external electric field. When the external electric field is weak and homogeneous, this expansion becomes:

$$
E=E^{0}-\frac{\mu_{i} F_{i}}{1 !}-\frac{\alpha_{i j} F_{i} F_{j}}{2 !}-\frac{\beta_{i j k} F_{i} F_{j} F_{k}}{3 !}-\frac{\gamma_{i j k l} F_{i} F_{j} F_{k} F_{l}}{4 !}+\cdots
$$

where $E$ is the energy of the unperturbed molecules, $F_{i}$ is the field at the orgin and $\mu_{i}, \alpha_{i j}, \beta_{i j k}$ and $\gamma_{i j k l}$ are the components of diple moment, polarizability and the hyperpolarizability, respectively. The total static dipole moment $(\mu)$, the mean polarizability $\left(\alpha_{0}\right)$, the anisotropy of the polarizability $\Delta \alpha$ and the mean first hyperpolarizability $\left(\beta_{0}\right)$, using the $x, y, z$ components they are defined as:

The total static dipole moment is

$$
\mu=\left(\mu_{x}^{2}+\mu_{y}^{2}+\mu_{z}^{2}\right)^{\frac{1}{2}}
$$

The isotropic polarizability is

$$
\alpha=\frac{\alpha_{x x}+\alpha_{y y}+\alpha_{z z}}{3}
$$

The polarizability anisotropy invariant is

$$
\Delta \alpha=2^{-1 / 2}\left[\left(\alpha_{x x}-\alpha_{y y}\right)^{2}+\left(\alpha_{y y}-\alpha_{z z}\right)^{2}+\left(\alpha_{z z}-\alpha_{x x}\right)^{2}+6 \alpha_{x x}^{2}\right]^{1 / 2}
$$

The average hyperpolarizability

$$
\beta_{t o t}=\left(\beta_{x}^{2}+\beta_{y}^{2}+\beta_{z}^{2}\right)^{1 / 2}
$$

Where

$$
\begin{aligned}
& \beta_{x}=\left(\beta_{x x x}+\beta_{x y y}+\beta_{x z z}\right) \\
& \beta_{y}=\left(\beta_{y y y}+\beta_{x x y}+\beta_{y z z}\right) \\
& \beta_{z}=\left(\beta_{z z z}+\beta_{x x z}+\beta_{y y z}\right)
\end{aligned}
$$

since the values of the polarizability and the hyperpolarizability of the Gaussian $09 \mathrm{~W}$ output are reported in atomic units (a.u.), the calculated values have been converted into electrostatic units (e.s.u.) $\left(1\right.$ a.u. $=0.3728 \times 10^{-30}$ e.s.u.). The total molecular dipole moment $(\mu)$ are 3.6992 debye (D), 3.6992 debye and calculated mean polarizabilty values are $0.3728 \times 10^{-30}$ and $0.83223 \times 10^{-30}$ e.s.u. in B3LYP method with $6-31+\mathrm{G}(\mathrm{d})$ and $6-311++\mathrm{G}(\mathrm{d}, \mathrm{p})$ values are presented in Table 1 . The hyperpolarizability of IPDP ipomparing with both basis sets, the B3LYP/6-311++G $(d, p)$ are greater than the B3LYP/6-31+G (d) method. 
Table 1. The eectric dipoe moment $(\mu)$ (debye), the mean poarizabiity $(\alpha)($ e.s.u. $)$, anisotropy poarizabiity $(\Delta \alpha)($ e.s.u. $)$ and first hyperpoarizabiity $\left(\beta_{\text {tot }}\right)$ (e.s.u.) for 4,4-isopropylidenebis (2,6-dichlorophenol) at B3LYP/6-31+G (d) and B3LYP/6-311++G (d, p) methods .

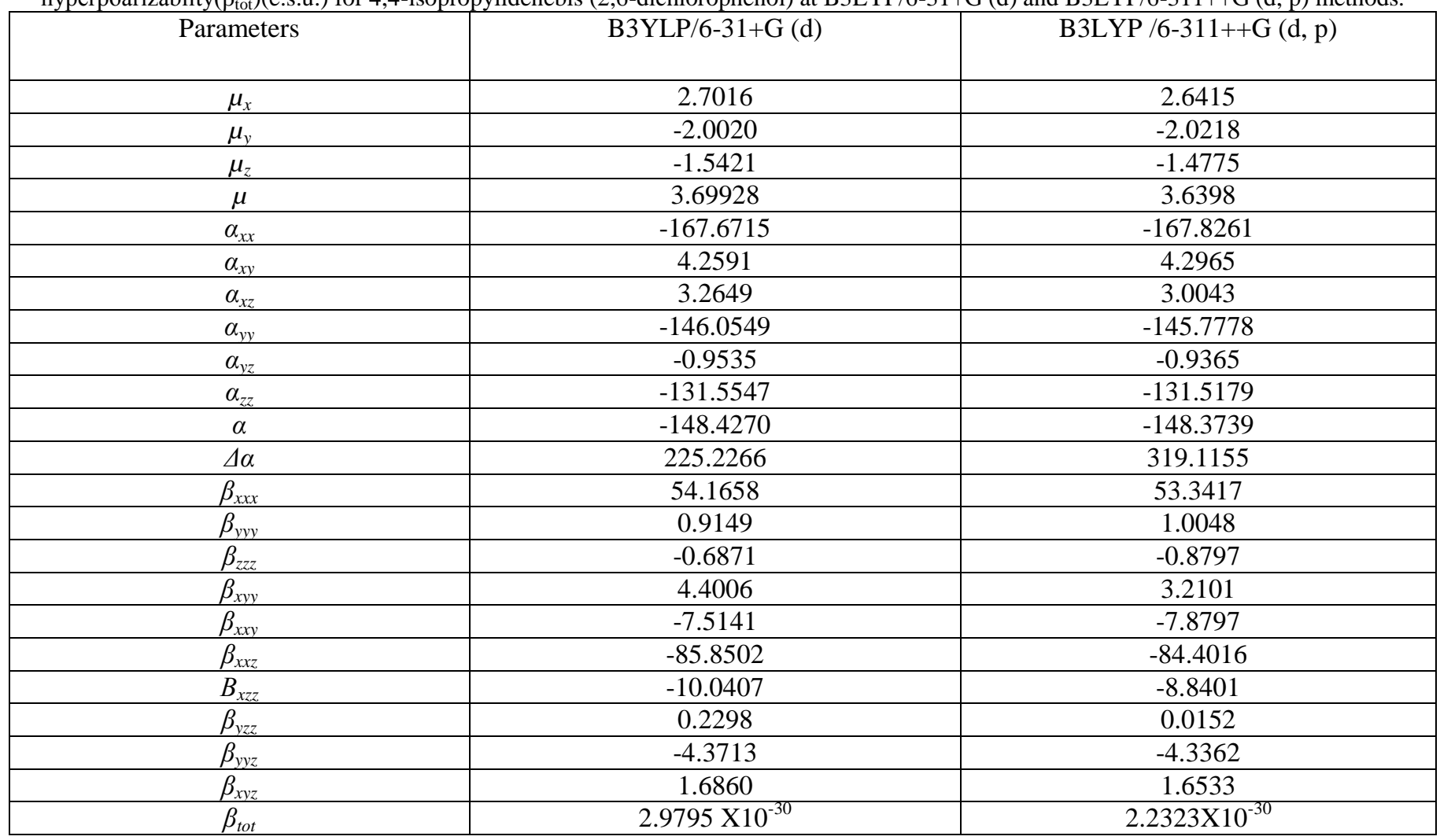

\section{RESULTS AND DISCUSSION}

\subsection{Molecular geometry}

In order to obtain the stable optimization geometry, the self consistent field (SCF) energy calculation is performed on the fifteen possible structures of optimization steps as shown in Fig. 1. The possibility of optimization geometry is found by locating NCO group of the title molecule in different orientations. The position of NCO group in different orientations gives rise to fifteen possible optimizations. Most of the more complicated structures have free internal structural parameter, which can either be taken from experiment or optimized using the calculated forces on the nuclei. Most optimization algorithm estimated or computed the value of the second derivative Hessian matrix of the energy with respect to the molecular coordinates, updating the matrix of force constants. The force constants specify the curvature of the surface at the point, which provides additional information useful for determining the next step. The predicted geometrical parameters such as, bond lengths, bond angles and dihedral angles of IPDP calculated at B3LYP/6-31+G (d) and B3LYP/6-311++G (d, p) level of theory are presented in Table 2 in accordance with atom numbering schemes given in Fig. 2. Since the exact crystal structure of IPDP is not available till now, the optimized structure can only be compared with other similar system for which the crystal structure have been solved. For comparative purpose, the theoritical data [4] are also presented. From the theoretical values we can find that most of the optimized bond lengths and bond angles are slightly larger or shorter than experimental values. Optimized structure yields fairly accurate bond length pairs for the bonds $\mathrm{C}_{1}-\mathrm{C}_{6}, \mathrm{C}_{2}-\mathrm{C}_{3}, \mathrm{C}_{6}-\mathrm{H}_{14}$ at DFT level of calculations. The values of bond lengths $\mathrm{C}_{2}-\mathrm{H}_{10}, \mathrm{C}_{3}-\mathrm{C}_{4}, \mathrm{C}_{5}-\mathrm{C}_{6}, \mathrm{C}_{5}-\mathrm{C}_{13}, \mathrm{O}_{7}-\mathrm{H}_{8}$, and $\mathrm{H}_{8}-\mathrm{Cl}_{9}$ are greater than literature values. The ring angle $\mathrm{C}_{4}-\mathrm{C}_{5}-\mathrm{C}_{6}$ is slightly less than ring angle $\mathrm{C}_{1}-\mathrm{C}_{2}-\mathrm{C}_{3}$. The breakdowns of hexagonal structure of the aromatic ring are obvious from the value of dihedral angles $\mathrm{O}_{7}-\mathrm{C}_{1}-\mathrm{C}_{2}-\mathrm{H}_{10}$ and $\mathrm{O}_{7}-\mathrm{C}_{1}-\mathrm{C}_{6}-\mathrm{H}_{14}$ are less than the literature values. Compared with $\mathrm{B} 3 \mathrm{LYP} / 6-31+\mathrm{G}(\mathrm{d})$ and B3LYP/6-311++G (d, p) level of the bond lengths, bond angles and dihedral angles differences between theoretical approaches have been shown in Figs.3,4, (Supplementary Materials) respectively. Optimization geometry is use to find the local minimum structure (LMS), global minimum structure (GMS) and the transition state structure (TSS). The optimized energy, maximum force and root mean square (RMS) force are presented in Table 2 


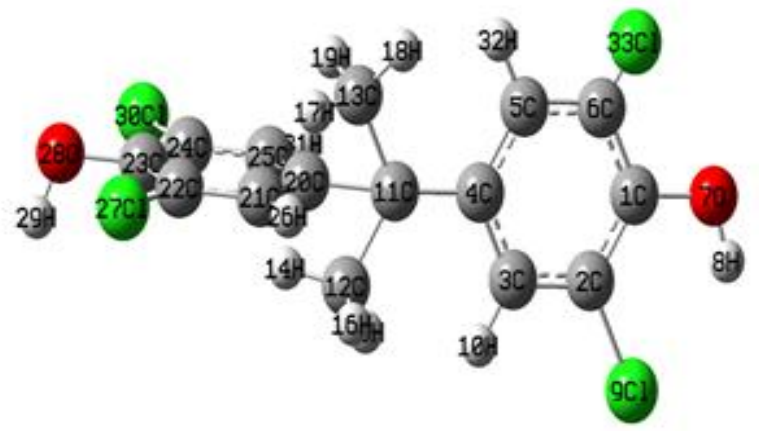

Fig.1. Possible conformational structures of of 4,4- isopropylidenebis(2,6-dichlorophenol)

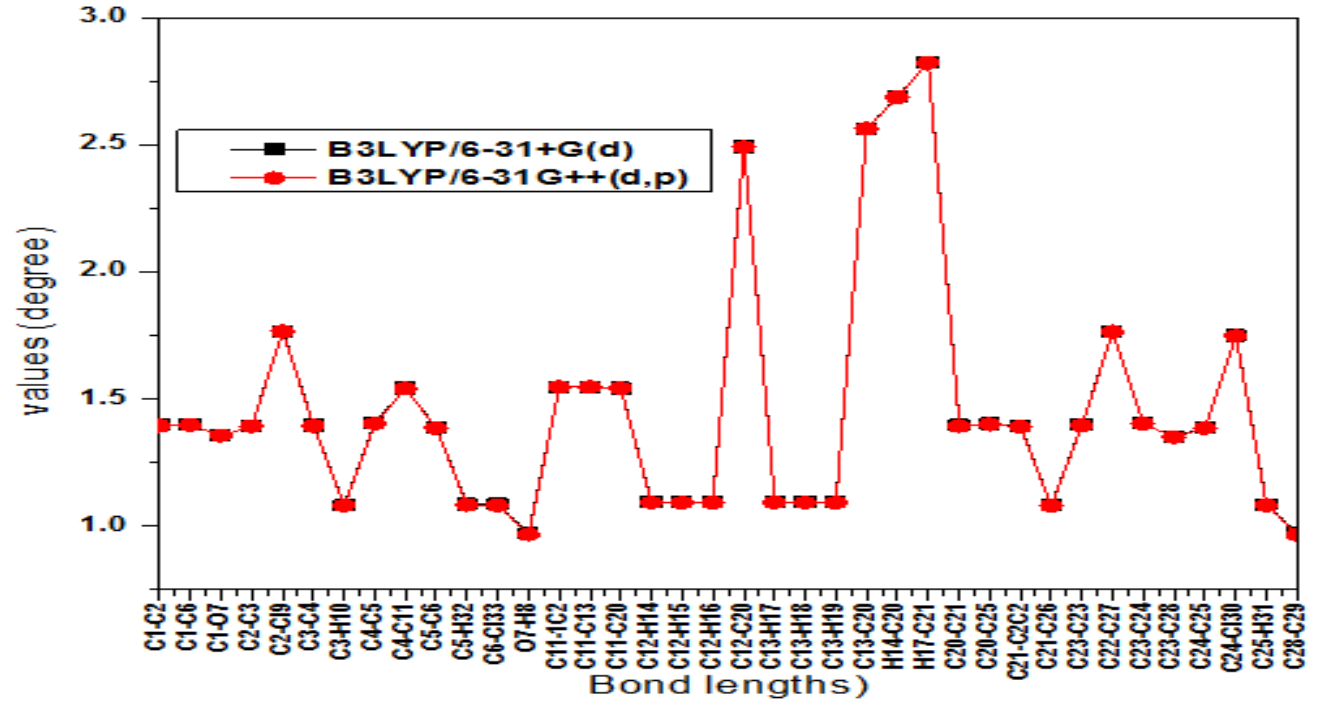

Fig.2. Bond length difference between the theoretical B3LYP/6 4,4- isopropylidenebis (2,6dichlorophenol)

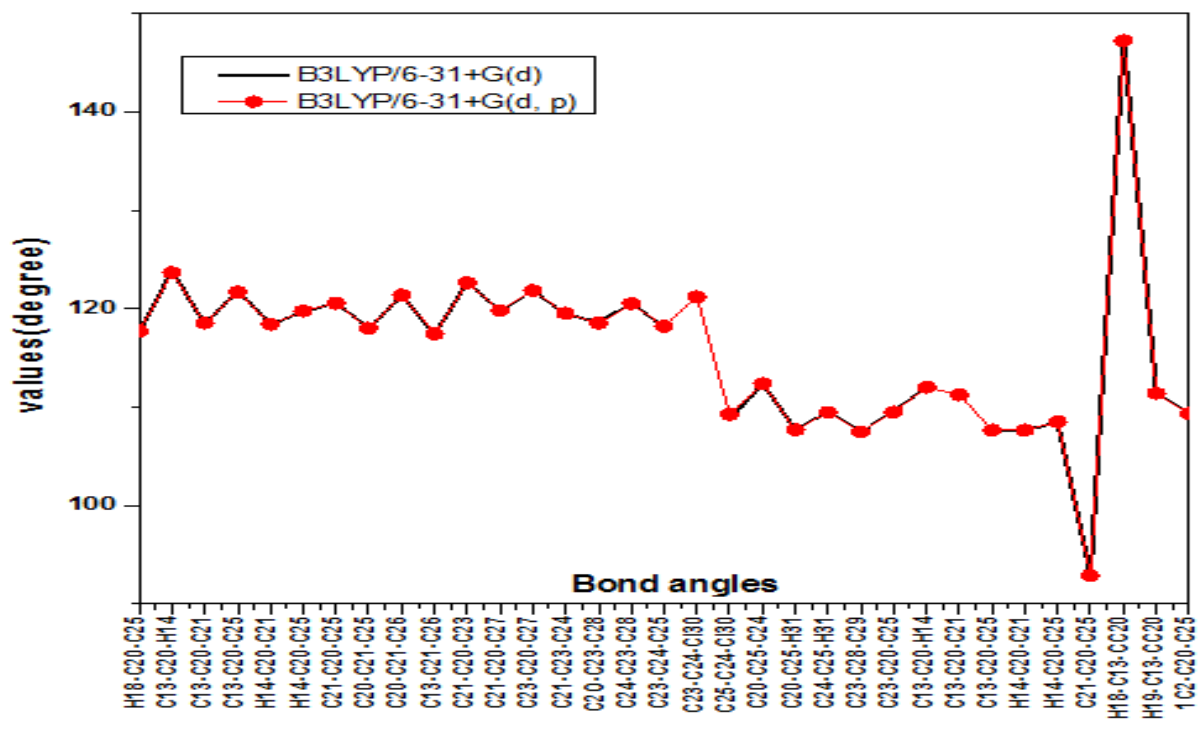

Fig.3. Bond angle differences between experimental and theoretical B3LYP/6-31+G (d) and B3LYP/6-311++G (d, p) of the 4,4-isopropylidenebis (2,6-dichlorophenol) 


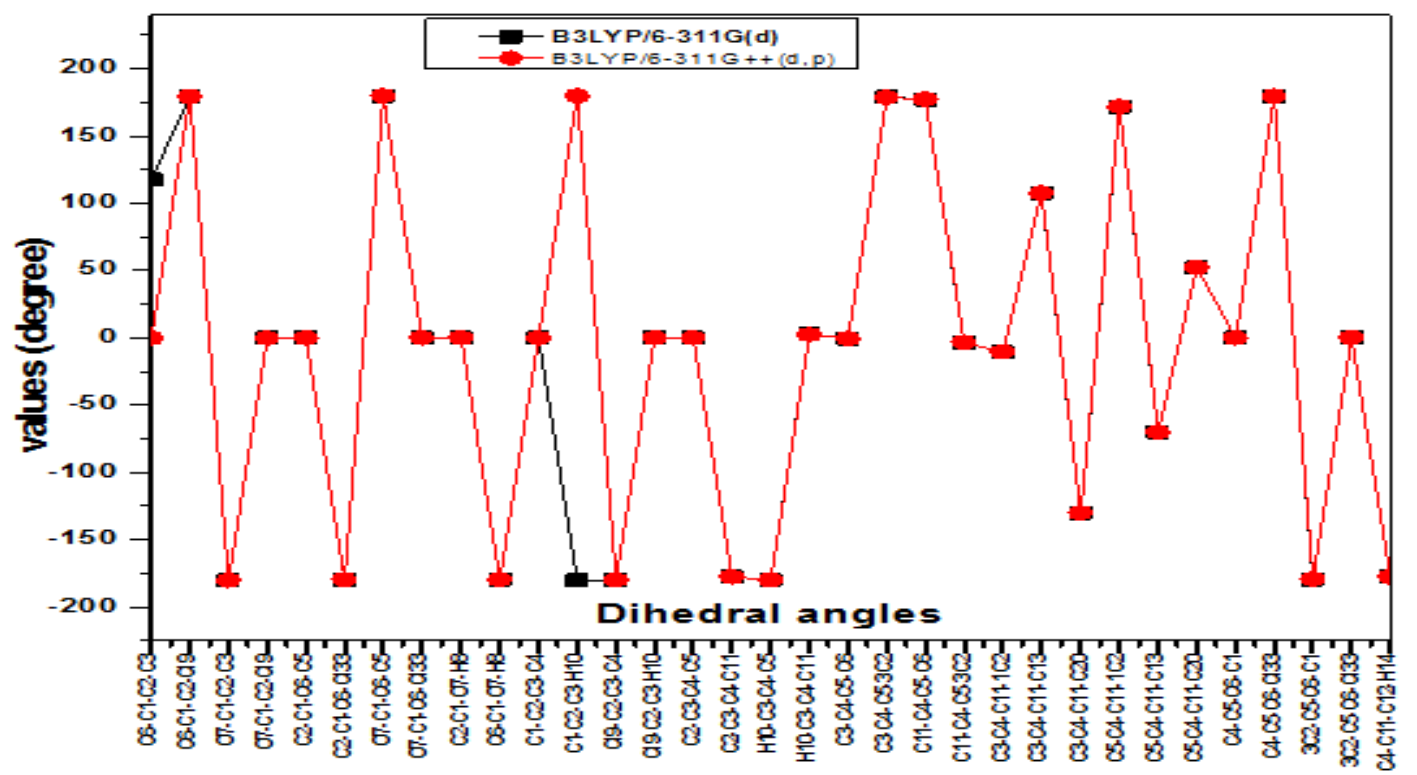

Fig.4. Dihedral angle differences between experimental and theoretical B3LYP/6-31+G (d) and B3LYP/6-311++G (d, p) of the 4 isopropylidenebis $(2,6$-dichlorophenol)

Table 2. Optimized geometrical parameters of 4,4-isopropylidenebis (2,6-dichlorophenol) by B3LYP/6-31+G (d) and B3LYP/6-311++G (d, p) methods.

\begin{tabular}{|c|c|c|c|c|c|c|c|c|}
\hline $\begin{array}{c}\text { Bond } \\
\text { Lengths }\end{array}$ & \multicolumn{2}{|c|}{$\frac{\text { Bond angles }}{\text { B3LYP }}$} & \multicolumn{6}{|c|}{ Values (degrees) } \\
\hline C1-C6 & 1.401 & 1.398 & C13-C20-H14 & 123.92 & 123.68 & C6-C1-C2-C19 & 179.75 & 179.658 \\
\hline $\mathrm{C} 1-\mathrm{O} 7$ & 1.356 & 1.357 & $\mathrm{C} 13-\mathrm{C} 20-\mathrm{C} 21$ & 118.44 & 118.56 & $\mathrm{O} 7-\mathrm{C} 1-\mathrm{C} 2-\mathrm{C} 3$ & -179.98 & -179.959 \\
\hline $\mathrm{C} 3-\mathrm{C} 4$ & 1.397 & 1.395 & $\mathrm{H} 14-\mathrm{C} 20-\mathrm{C} 25$ & 119.74 & 119.774 & C2-C1-C6-C133 & -179.58 & -179.548 \\
\hline C3-H10 & 1.083 & 1.081 & $\mathrm{C} 21-\mathrm{C} 20-\mathrm{C} 25$ & 120.60 & 120.587 & O7-C1-C6-C5 & 179.92 & 179.904 \\
\hline $\mathrm{C} 4-\mathrm{C} 5$ & 1.407 & 1.404 & $\mathrm{C} 20-\mathrm{C} 21-\mathrm{C} 25$ & 118.05 & 118.023 & O7-C1-C6-Cl33 & $0 . \mathrm{C} 24$ & 0.221 \\
\hline C4-C11 & 1.542 & 1.541 & $\mathrm{C} 20-\mathrm{C} 21-\mathrm{C} 26$ & 121.35 & 121.390 & C2-C1-O7-H8 & 0.18 & 0.195 \\
\hline $\mathrm{C} 5-\mathrm{C} 6$ & 1.388 & 1.386 & $\mathrm{C} 13-\mathrm{C} 21-\mathrm{C} 26$ & 117.45 & 117.468 & C6-C1-O7-H8 & -179.64 & -179.559 \\
\hline C5-H32 & 1.086 & 1.084 & C21-C20-C23 & 122.72 & 122.668 & C1-C2-C3-C4 & 0.03 & 0.046 \\
\hline $\mathrm{C} 11-\mathrm{C} 20$ & 1.542 & 1.542 & C24-C23-C28 & 120.58 & 120.532 & C2-C3-C4-C11 & -177.35 & -177.534 \\
\hline C12-H14 & 1.095 & 1.092 & C23-C24-C25 & 118.13 & 118.238 & H10-C3-C4-C5 & -179.82 & -179.770 \\
\hline C12-H15 & 1.095 & 1.092 & $\mathrm{C} 23-\mathrm{C} 24-\mathrm{Cl} 30$ & 121.C30 & 121.230 & $\mathrm{H} 10-\mathrm{C} 3-\mathrm{C} 4-\mathrm{C} 11$ & 2.67 & 2.520 \\
\hline C12-H16 & 1.096 & 1.093 & $\mathrm{C} 25-\mathrm{C} 24-\mathrm{Cl} 30$ & 108.77 & 109.284 & C3-C4-C5-C6 & $-0 . C 24$ & -0.245 \\
\hline C12-C20 & 2.493 & 2.492 & C20-C25-C24 & 112.39 & 112.407 & C3-C4-C5-C2 & 179.02 & 178.979 \\
\hline C13-H17 & 1.096 & 1.094 & $\mathrm{C} 20-\mathrm{C} 25-\mathrm{H} 31$ & 107.69 & 107.711 & C11-C4-C5-C6 & 177.35 & 177.533 \\
\hline C13-H18 & 1.095 & 1.092 & C24-C25-H31 & 109.57 & 109.476 & C11-C4-C5-C2 & -3.39 & -3.243 \\
\hline C13-H19 & 1.095 & 1.092 & C23-C28-C29 & 107.50 & 107.499 & C3-C4-C11-C2 & -10.62 & -10.292 \\
\hline C13-C20 & 2.564 & 2.564 & $\mathrm{C} 23-\mathrm{C} 20-\mathrm{C} 25$ & 109.61 & 109.511 & C3-C4-C11-C13 & 107.58 & 107.945 \\
\hline H14-C20 & 2.690 & 2.688 & C13-C20-H14 & 112.03 & 112.049 & C3-C4-C11-C20 & -130.17 & -129.808 \\
\hline H17-C21 & 2.824 & 2.823 & C13-C20-C21 & 111.028 & 111.262 & C5-C4-C11-1C2 & 171.92 & 172.051 \\
\hline
\end{tabular}




\begin{tabular}{|c|c|c|c|c|c|c|c|c|}
\hline C21-C22 & 1.394 & 1.391 & H14-C20-C25 & 108.42 & 108.511 & C4-C5-C6-C1 & 0.11 & 0.090 \\
\hline C21-C26 & 1.083 & 1.081 & C21-C20-C25 & 92.96 & 92.887 & C4-C5-C6-Cl33 & 179.78 & 179.763 \\
\hline $\mathrm{C} 23-\mathrm{C} 23$ & 1.400 & 1.396 & H18-C13-CC20 & 147. C27 & 147.246 & 3C2-C5-C6-C1 & -179.16 & -179.141 \\
\hline C22-C27 & 1.766 & 1.765 & H19-C13-CC20 & 111.48 & 111.435 & 3C2-C5-C6-Cl33 & 0.51 & 0.532 \\
\hline C23-C24 & 1.406 & 1.403 & 1C2-C20-C25 & 109.39 & 109.321 & $\begin{array}{l}\text { C4-C11-C12- } \\
\text { H14 }\end{array}$ & -177.53 & -177.555 \\
\hline C23-C28 & 1.351 & 1.351 & C13-C20-H14 & 112.07 & 112.083 & $\begin{array}{l}\text { C4-C11-C12- } \\
\text { H15 }\end{array}$ & -58.06 & -58.158 \\
\hline C24-C25 & 1.388 & 1.386 & C13-C20-C21 & 107.65 & 107.668 & $\begin{array}{l}\text { C4-C11-C12- } \\
\text { H16 }\end{array}$ & 63.50 & 63.521 \\
\hline $\mathrm{C} 24-\mathrm{Cl} 30$ & 1.750 & 1.749 & C13-C20-C25 & 108.48 & 108.565 & $\begin{array}{l}\text { C13-C11-C12- } \\
\text { H14 }\end{array}$ & 64.15 & 64.084 \\
\hline C25-H31 & 1.085 & 1.083 & H14-C20-C21 & 94.04 & 93.994 & $\begin{array}{l}\text { C13-C11-C12- } \\
\text { H15 }\end{array}$ & -176.38 & -176.519 \\
\hline \multirow[t]{9}{*}{ C28-C29 } & 0.973 & 0.967 & H14-C20-C25 & 107.61 & 107.599 & $\begin{array}{l}\text { C13-C11-C12- } \\
\text { H16 }\end{array}$ & -54.82 & -54.841 \\
\hline & & & C21-C20-C25 & 143.20 & 143.127 & $\begin{array}{l}\text { C4-C11-C13- } \\
\text { H17 }\end{array}$ & -176.18 & -176.271 \\
\hline & & & C20-C21-C22 & 92.47 & 92.541 & $\begin{array}{l}\text { C4-C11-C13- } \\
\text { H18 }\end{array}$ & $-57 . C 24$ & -57.378 \\
\hline & & & C20-C21-C26 & 53.94 & 53.871 & $\begin{array}{l}\text { C4-C11-C13- } \\
\text { H19 }\end{array}$ & 62.01 & 61.832 \\
\hline & & & $\mathrm{C} 2 \mathrm{C} 2-\mathrm{C} 21-\mathrm{C} 26$ & 122.88 & 122.845 & $\begin{array}{l}\text { 1C2-C11-C13- } \\
\mathrm{H} 17\end{array}$ & -54.87 & -54.921 \\
\hline & & & $\mathrm{C} 21-\mathrm{C} 2 \mathrm{C} 2-\mathrm{C} 23$ & 119.34 & 119.336 & $\begin{array}{l}\text { 1C2-C11-C13- } \\
\text { H18 }\end{array}$ & 64.07 & 63.972 \\
\hline & & & $\mathrm{C} 21-\mathrm{C} 2 \mathrm{C} 2-\mathrm{C} 27$ & 59.13 & 59.114 & $\begin{array}{l}\text { 1C2-C11-C13- } \\
\text { H19 }\end{array}$ & -176.68 & -176.819 \\
\hline & & & C23-C2C2-C27 & 125.92 & 126.118 & $\begin{array}{l}\text { C4-C11-C20- } \\
\text { H14 }\end{array}$ & 145.84 & 145.858 \\
\hline & & & $\mathrm{C} 2 \mathrm{C} 2-\mathrm{C} 23-\mathrm{C} 24$ & 102.62 & 102.522 & $\mathrm{C} 4-\mathrm{C} 11-\mathrm{C} 20-\mathrm{C} 21$ & -130.09 & -129.737 \\
\hline
\end{tabular}

\subsection{Vibrational spectral analysis}

The optimized structural parameters were used to compute the vibrational frequencies of IPDP at the DFT (B3LYP)/6-31+G (d) and $6-311++\mathrm{G}(\mathrm{d}, \mathrm{p})$ level of calculation. The title molecule contains 33 atoms and belongs to $\mathrm{C}_{1}$ symmetry point group. Hence the number of normal modes of vibrations for IPDP works to 93. Of the normal modes of vibrations, 63 modes of vibrations are in-plane modes and 30 modes of vibrations are out-of-plane modes are represented.

All the 93 fundamental vibrations are active in Raman scattering and infrared absorption. Detailed description of vibrational modes can be given by means of normal coordinate analysis. Comparison of the frequencies calculated at B3LYP/6-31+G (d) and B3LYP/6-311++G $(\mathrm{d}, \mathrm{p})$ levels with experimental values reveals the over estimation of the calculated vibrational modes. Inclusion of certain extent makes the B3LYP/6-311++G (d, p) values smaller in comparison to the B3LYP/6-31+G (d) frequency data. Reduction in computed harmonic vibrational frequencies through basis set sensitive are only marginal as observed in the DFT values using 6-311++G $(\mathrm{d}, \mathrm{p})$. Anyway, notwithstanding the level of calculations, it is customary to scaling down the computed harmonic frequencies in order to good improve the agreement with the experimental data. Root mean square (RMS) values of frequencies were obtained in the study using the following experessions.

$$
\mathrm{RMS}=\sqrt{\frac{1}{n-1} \sum_{i}^{n}\left(v_{i}^{\mathrm{calc}}-v_{i}^{\text {exp }}\right)^{2}}
$$

The RMS error between unscaled and experimental frequencies is $103 \mathrm{~cm}^{-1}$ by B3LYP/6-31+G (d) and $81 \mathrm{~cm}^{-1}$ by B3LYP/6$311++\mathrm{G}(\mathrm{d}, \mathrm{p})$. However, for reliable information on the vibrational properties the use of a selective scaling is necessary. The calculated frequencies are scaled using the set of transferable scale factors recommended by Rauhut and Pulay [12] and resulted in a RMS deviation of $7 \mathrm{~cm}^{-1}$ by B3LYP/6-31+G (d) and $5 \mathrm{~cm}^{-1}$ by B3LYP/6-311++G $(\mathrm{d}, \mathrm{p})$. The observed FT-IR and FT-Raman spectra of the title molecule along with the simulated IR and Raman spectra are shown in Figs. 5 respectively. The observed FT-IR, FT-Raman wavenumbers and the calculated wavenumbers using density functional B3LYP method with 6$31+\mathrm{G}(\mathrm{d})$ and $6-311++\mathrm{G}(\mathrm{d}, \mathrm{p})$ basis sets along with their relative intensities, probable assignments of the compound are summarized in Table 3. 

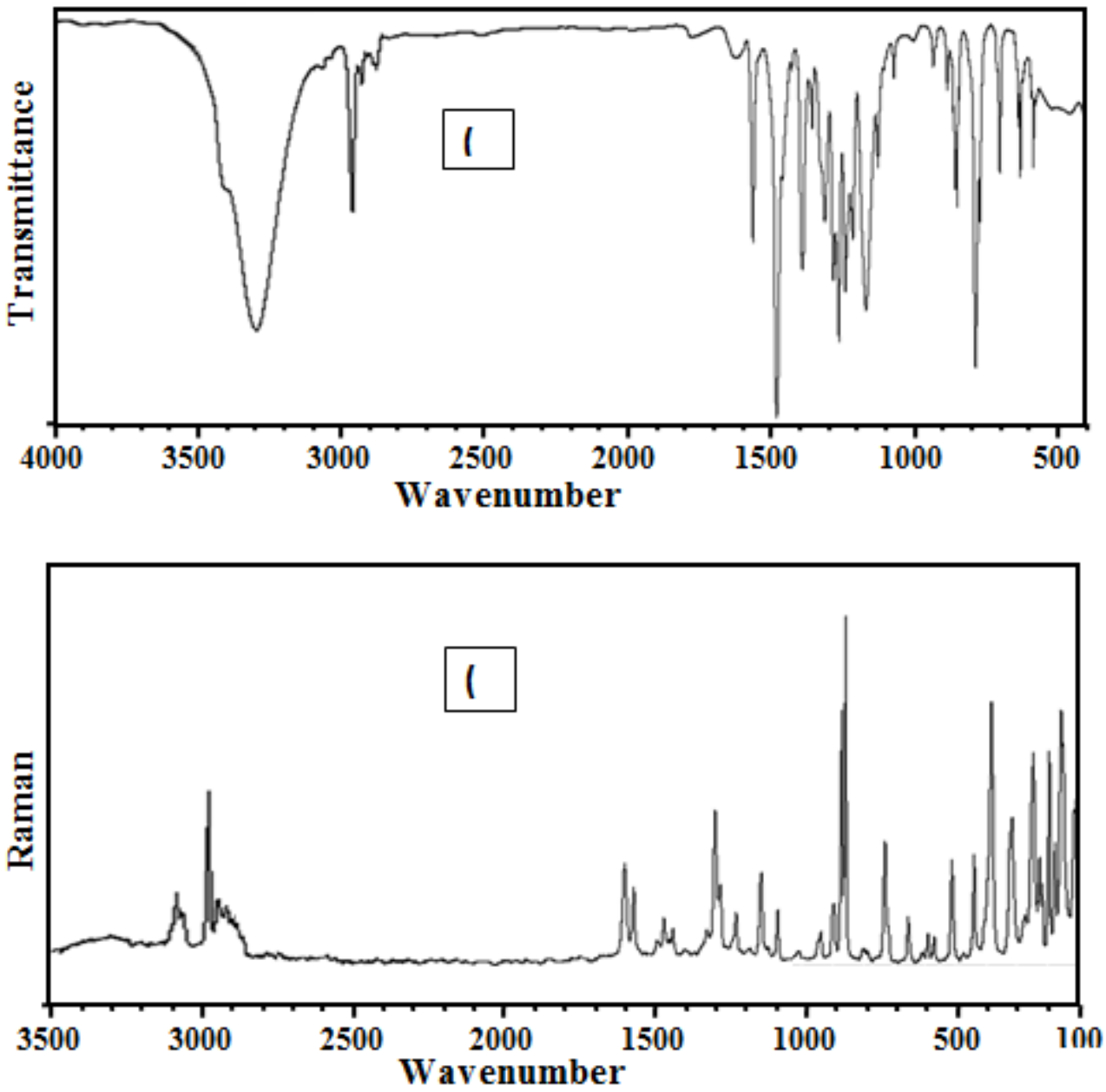

Fig. 5. Observed (a) FT-IR and (b) FT-Raman spectra of 4, 4-isopropylidenebis (2,6-dichlorophenol)

Table 3. Vibrational assignments of FT-IR and FT-Raman peaks along the theoreticallay computed wavenumbers, IR intensity $\left(I_{I R}\right)$ and Raman intensity $\left(I_{\text {Raman }}\right)$ and the percentage of potential energy distribution.

\begin{tabular}{|c|c|c|c|c|c|c|c|c|c|c|c|c|}
\hline \multirow[t]{3}{*}{ S.No } & \multirow[t]{3}{*}{ Species } & \multicolumn{2}{|c|}{$\begin{array}{l}\text { Observed wave } \\
\text { number }\left(\mathrm{cm}^{-1}\right)\end{array}$} & \multicolumn{8}{|c|}{ Cacuated wave number $\left(\mathrm{cm}^{-1}\right)$} & \multirow{3}{*}{$\begin{array}{c}\text { Assignments } \\
\text { with \% of } \\
\text { PED }^{c}\end{array}$} \\
\hline & & \multirow{2}{*}{$\begin{array}{l}\text { FT- } \\
\text { IR }\end{array}$} & \multirow{2}{*}{$\begin{array}{c}\text { FT- } \\
\text { Raman }\end{array}$} & \multicolumn{4}{|c|}{ B3YP/6-31+G (d) } & \multicolumn{4}{|c|}{ B3LYP/6-311`++G (d, p) } & \\
\hline & & & & Unscaed & Scaed $^{b}$ & $I_{I R}$ & $I_{\text {Raman }}$ & Unscaed & Scaed $^{b}$ & $I_{I R}$ & $I_{\text {Raman }}$ & \\
\hline 2 & $\mathrm{~A}$ & & & 3697 & 4498 & 101.08 & 80.033 & 3763 & 3499 & 75.10 & 122.04 & vO-H(99) \\
\hline 3 & $\mathrm{~A}$ & & 3073 & 3244 & 3080 & 00.30 & 48.875 & 3219 & 3071 & 46.85 & 0.09 & $\mathrm{CH} 3$ ass(98) \\
\hline 4 & $\mathrm{~A}$ & & 3068 & 3238 & 3070 & 0.67 & 50.776 & 3214 & 3065 & 49.99 & 0.19 & CH3 ass(99) \\
\hline 7 & $\mathrm{~A}$ & & & 3198 & 3040 & 8.31 & 40.455 & 3175 & 3036 & 39.28 & 6.34 & vCH(97 \\
\hline 8 & A & & & 3132 & 3028 & 28.13 & 70.810 & 3106 & 3027 & 66.23 & 26.75 & vCH(99) \\
\hline 9 & $\mathrm{~A}$ & 2968 & & 3132 & 3026 & 5.16 & 67.801 & 3105 & 3025 & 54.09 & 21.08 & vCH(98) \\
\hline 10 & $\mathrm{~A}$ & 2958 & 2958 & 3124 & 2963 & 8.31 & 101.420 & 3099 & 2960 & 113.98 & 52.21 & vCH(97) \\
\hline 16 & A & 1580 & & 1629 & 1579 & 24.33 & 5.959 & 1612 & 1576 & 7.53 & 19.43 & vCC(86) \\
\hline
\end{tabular}




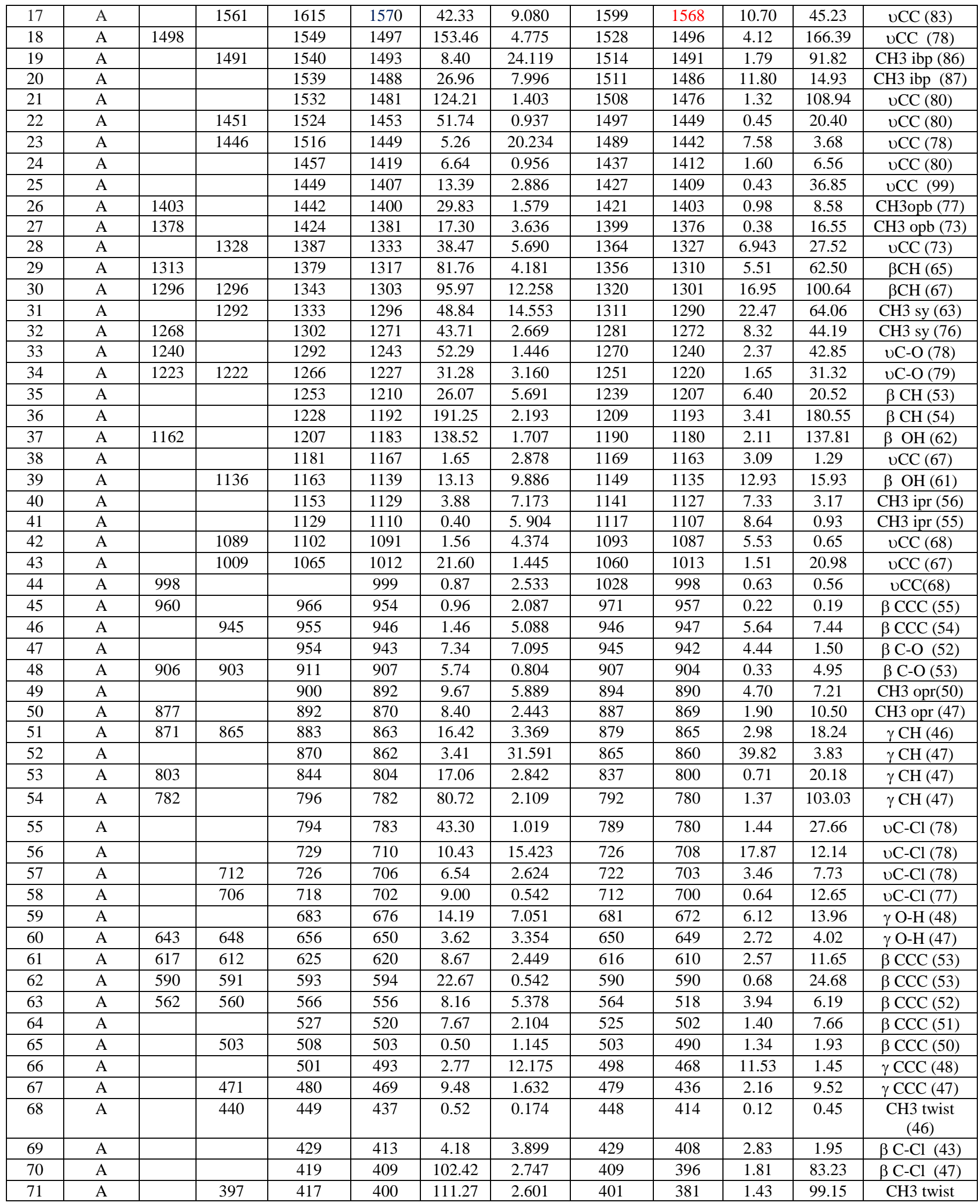




\begin{tabular}{|c|c|c|c|c|c|c|c|c|c|c|c|c|}
\hline & & & & & & & & & & & $(37)$ \\
\hline 72 & $\mathrm{~A}$ & & & 389 & 380 & 1.75 & 1.829 & 386 & 378 & 2.32 & 3.15 & $\beta \mathrm{C}-\mathrm{Cl}(40)$ \\
\hline 73 & $\mathrm{~A}$ & & & 384 & 379 & 1.19 & 2.699 & 382 & 368 & 1.49 & 4.05 & $\beta \mathrm{C}-\mathrm{Cl}(42)$ \\
\hline 74 & $\mathrm{~A}$ & & & 378 & 370 & 1.60 & 5.950 & 377 & 368 & 5.40 & 1.47 & $\gamma \mathrm{CCC}(43)$ \\
\hline 75 & $\mathrm{~A}$ & & & 340 & 333 & 1.33 & 0.975 & 335 & 332 & 1.18 & 2.06 & $\gamma \mathrm{CCC}(43)$ \\
\hline 76 & $\mathrm{~A}$ & & & 330 & 327 & 0.48 & 1.415 & 325 & 326 & 2.02 & 0.46 & $\gamma \mathrm{CCC}(44)$ \\
\hline 77 & $\mathrm{~A}$ & & 308 & 322 & 308 & 1.22 & 2.400 & 317 & 206 & 2.79 & 1.30 & $\gamma \mathrm{CCC}(42)$ \\
\hline 78 & $\mathrm{~A}$ & & & 302 & 297 & 4.71 & 0.444 & 295 & 296 & 0.48 & 4.55 & $\gamma \mathrm{CC}(40)$ \\
\hline 79 & $\mathrm{~A}$ & & & 293 & 286 & 0.71 & 1.202 & 287 & 287 & 1.35 & 0.84 & $\gamma \mathrm{C}-\mathrm{O}(44)$ \\
\hline 80 & $\mathrm{~A}$ & & 273 & 286 & 278 & 3.07 & 1.117 & 280 & 277 & 1.45 & 3.33 & $\gamma \mathrm{C}-\mathrm{Cl}(41)$ \\
\hline 81 & $\mathrm{~A}$ & & 250 & 264 & 753 & 0.44 & 1.125 & 262 & 752 & 1.47 & 0.51 & $\gamma \mathrm{C}-\mathrm{Cl}(43)$ \\
\hline 82 & $\mathrm{~A}$ & & 223 & 251 & 219 & 0.46 & 0.512 & 248 & 218 & 0.47 & 0.63 & $\gamma \mathrm{C}-\mathrm{Cl}(48)$ \\
\hline 83 & $\mathrm{~A}$ & & & 219 & 210 & 0.43 & 1.341 & 214 & 207 & 0.95 & 0.21 & $\gamma \mathrm{C}-\mathrm{Cl}()$ \\
\hline 84 & $\mathrm{~A}$ & & 200 & 207 & 201 & 0.27 & 2.444 & 205 & 196 & 2.04 & 0.20 & $\gamma \mathrm{C}-\mathrm{Cl}()$ \\
\hline 85 & $\mathrm{~A}$ & & 176 & 179 & 173 & 0.05 & 2.736 & 176 & 169 & 1.95 & 0.03 & $\gamma \mathrm{C}-\mathrm{O}()$ \\
\hline 86 & $\mathrm{~A}$ & & & 170 & 167 & 0.10 & 0.661 & 167 & 163 & 0.55 & 0.22 & $\gamma \mathrm{CCC}(43)$ \\
\hline 87 & $\mathrm{~A}$ & & 150 & 158 & 148 & 0.09 & 1.615 & 156 & 143 & 1.44 & 0.12 & $\gamma \mathrm{CCC}(44)$ \\
\hline 88 & $\mathrm{~A}$ & & & 138 & 133 & 0.01 & 2.079 & 136 & 105 & 1.72 & 0.02 & $\gamma \mathrm{CCC}(42)$ \\
\hline 89 & $\mathrm{~A}$ & & & 109 & 108 & 0.06 & 0.214 & 106 & 107 & 0.16 & 0.08 & $\gamma \mathrm{CC}(40)$ \\
\hline 90 & $\mathrm{~A}$ & & & 101 & 97 & 0.19 & 0.496 & 99 & 96 & 0.33 & 0.11 & $\gamma \mathrm{CCC}(43)$ \\
\hline 91 & $\mathrm{~A}$ & & & 43 & 42 & 0.05 & 6.439 & 42 & 41 & 4.92 & 0.03 & $\gamma \mathrm{CCC}(44)$ \\
\hline 92 & $\mathrm{~A}$ & & & 23 & 20 & 0.02 & 4.047 & 21 & 20 & 3.18 & 0.01 & $\gamma \mathrm{CCC}(42)$ \\
\hline 93 & $\mathrm{~A}$ & & & 21 & 19 & 0.03 & 2.637 & 18 & 18 & 1.91 & 0.05 & $\gamma \mathrm{CC}(40)$ \\
\hline
\end{tabular}

\subsection{Vibrational assignments: \\ Aromatic ring breathing modes}

Benzene ring is frequently encountered in organic chemistry. Although we write benzene as a six-membered ring with three double bonds, this is not a good representation of the structure of the molecule. The vibrational motions of a benzene ring are not isolated but involve the entire molecule. To describe one of the fundamental motions of benzene, consider some imaginary lines passing through the centre of the molecule and extending out through each carbon atom and beyond. A symmetric stretching and compression of all the carbon atoms of benzene along each line is an example of the ring breathing motion. Simultaneous expansions and compressions of these six carbon atoms lead to other ring-breathing motions [13]. The ring $\mathrm{C}=\mathrm{C}$ and C-C stretching vibrations, known as semicircle stretching modes usually occurs in the region $1580 \mathrm{~cm}^{-1}$ [14-15]. In general, the bands are of variable intensity and are observed $1590-1575 \mathrm{~cm}^{-1}, 1540-1470 \mathrm{~cm}^{-1}, 1465-1430 \mathrm{~cm}^{-1}$ and $1380-1280 \mathrm{~cm}^{-1}$ from the frequency ranges given by Varsanyi [16] for the five bands in the region. In the present work, the frequencies observed in FT-IR spectrum at 1585, 1552, 1521, 1424 and $1296 \mathrm{~cm}^{-1}$ have been assigned to C-C stretching vibrations. The corresponding vibration appears in the FT-Raman spectrum at 1606, 1561, 1451,1446, 1398 and $1296 \mathrm{~cm}^{-1}$. All the bands lie in the expected range when compared to the literature values. The $\mathrm{C}-\mathrm{C}$ aromatic stretch, known as semicircle stretching, predicted at $1556 \mathrm{~cm}^{-1}$ is in reasonable agreement with the band observed at 1552 and $1550 \mathrm{~cm}^{-1}$ in FT-IR and FT-Raman spectra. The CCC in-plane bending vibrations observed at 998, 960, 567 and $541 \mathrm{~cm}^{-1}$ in FT-IR spectra. The corresponding values appear in the FT-Raman spectra at 909, 878, 564 and $536 \mathrm{~cm}^{-1}$. The CCC out-of-plane bending vibrations appeared at $308 \mathrm{~cm}^{-1}$. These assignments are in good agreement with the literature $[17,18]$. These observed frequencies show that, the substitutions in the benzene ring to some extend affect the ring modes of vibrations. The theoretically computed values by B3LYP/6-31+G (d) and B3LYP/6-311++G $(\mathrm{d}, \mathrm{p})$ methods are in good agreement with experimental values.

\section{C-H vibrations}

Consider the carbon-hydrogen stretching frequencies. If we assume that all $\mathrm{C}-\mathrm{H}$ stretching force constants are similar in magnitude, we would expect the stretching frequencies of all $\mathrm{C}-\mathrm{H}$ bonds to be similar. This expectation is based on the fact that the mass of a carbon atom and whatever else is attached to the carbon is much larger than the mass of hydrogen. The reduced mass for vibration of a hydrogen atom would be approximately the mass of hydrogen atom that is independent of the structure. All C-H stretching modes are observed at approximately $3000 \mathrm{~cm}^{-1}$, exactly as expected. Fortunately, the force constants do vary with structure in a fairly predictable manner, and therefore it is possible to differentiate between different types of $\mathrm{C}-\mathrm{H}$ bonds. Generally, the aromatic C-H vibrations are normally found between $3100-3000 \mathrm{~cm}^{-1}[19,20]$. However, as with any complex molecule, vibration interactions occur and these levels only indicate the predominant vibration. Substituted benzenes, i.e., bonds whose position is significantly affected by the mass and electronic properties, mesmeric or inductive of the substituent. Since, IPDP is a tri-substituted aromatic system; it has three $\mathrm{C}-\mathrm{H}$ moiety. The aromatic structure shows the 
presence of C-H stretching vibrations assigned at 3073, $3068 \mathrm{~cm}^{-1}$ in FT-IR spectra and 3040 , and $3028 \mathrm{~cm}^{-1}$ in FT-Raman spectra. The aromatic C-H in-plane bending modes of benzene and its derivatives are observed in the region $1300-1000 \mathrm{~cm}^{-1}$ [21]. These modes are in the FT-IR spectrum of the title molecule at 1313, 1223, and $1023 \mathrm{~cm}^{-1}$ and the corresponding modes are identified in the FT-Raman spectrum at 865,860 and $806 \mathrm{~cm}^{-1}$. The out-of-plane bending mode of benzene derivatives are generally observed in the region $1000-600 \mathrm{~cm}^{-1}$ [22]. Accordingly to the PED results, the prominent absorption peaks at 998 , 960,877 , and $712 \mathrm{~cm}^{-1}$ in FT-IR and 877, 870,860 and $804 \mathrm{~cm}^{-1}$ in FT-Raman are assigned to C-H out-of-plane bending modes were also assigned within the characteristic region and are presented in Table 6 , respectively.

\section{C-Cl vibrations}

The $\mathrm{C}-\mathrm{Cl}$ stretching vibrations give generally strong bands in the region $800-600 \mathrm{~cm}^{-1}$ [23]. The vibrations belonging to the bond between the ring and halogen atoms were worth the discussion here since the mixing of vibrations are possible due to the lowering of the molecular symmetry and the presence of heavy atoms on the periphery of molecule [24]. In the present study, $\mathrm{C}-\mathrm{Cl}$ stretching vibration observed at 782 and $784 \mathrm{~cm}^{-1}$ in FT-IR spectra and corresponding modes are identified in the FTRaman spectrum at 808, 776 and $674 \mathrm{~cm}^{-1}$. The $\mathrm{C}-\mathrm{Cl}$ in-plane bending mode of DCPI is observed at $442 \mathrm{~cm}^{-1}$ in FT-IR and 438 and $318 \mathrm{~cm}^{-1}$ in FT-Raman spectrum. The band observed at 250, 223 and $200 \mathrm{~cm}^{-1}$ in FT-Raman is due to C-Cl out-of-plane bending. These assignments are in good agreement with the literature $[25,26]$ as well as computed values by B3LYP method with $6-31+\mathrm{G}(\mathrm{d})$ and $6-311++\mathrm{G}(\mathrm{d}, \mathrm{p})$ basis sets.

\section{Methyl vibrations}

Methyl groups are generally referred to an electron-donating substituent's in the aromatic ring system. For the assignments of $\mathrm{CH}_{3}$ group frequencies on can expect nine fundamentals can be associated to each $\mathrm{CH}_{3}$ group, namely the asymmetrical stretching $\left(\mathrm{CH}_{3} \mathrm{ass}\right)$, symmetrical stretching $\left(\mathrm{CH}_{3} \mathrm{Ss}\right)$, in-plane bending $\left(\mathrm{CH}_{3} \mathrm{ipb}\right)$, out-of-plane bending $\left(\mathrm{CH}_{3} \mathrm{Opb}\right)$, symmetric bending $\left(\mathrm{CH}_{3} \mathrm{sb}\right)$, in-plane rocking $\left(\mathrm{CH}_{3} \mathrm{ipr}\right)$, out-of-plane rocking $\left(\mathrm{CH}_{3} \mathrm{opr}\right)$ and twisting $\left(\mathrm{CH}_{3}\right.$ twist $)$ modes. Whenever a methyl group is present in a compound, it gives rise to two asymmetric and one symmetric stretching is usually at higher wavenumber than the symmetric stretching. The asymmetric stretching vibrations of $\mathrm{CH}_{3}$ are expected in the region $3000-2925 \mathrm{~cm}^{-1}$ and symmetric $\mathrm{CH}_{3}$ stretching vibrations in the range $2940-2905 \mathrm{~cm}^{-1}$ [27,28]. The observed asymmetric and symmetric stretching vibrations for $\mathrm{CH}_{3}$ are at 3000 and $2966 \mathrm{~cm}^{-1}$ in FT-IR band and at 3000 and $2928 \mathrm{~cm}^{-1}$ in FT-Raman band. The calculated asymmetric and symmetric modes are 3073, 3068, 2958, and $2948 \mathrm{~cm}^{-1}$ at B3LYP 30803070, 3060 and $1296,1292 \mathrm{~cm}^{-1}$ at methods are good agreement with observed data's. Two bending modes can occur within a methyl group. The first of these, the symmetric bending vibration, involves the in-phase of $\mathrm{C}-\mathrm{H}$ bonds. The second the asymmetric bending vibrations, involves out-of-phase of the $\mathrm{C}-\mathrm{H}$ bonds. The $\mathrm{CH}_{3}$ in-plane bending vibrations are expected in the region 1485-1400 $\mathrm{cm}^{-1}$ [29]. The FT-IR band observed at $1486 \mathrm{~cm}^{-1}$ and the out-of-plane bending vibration coupled with $\mathrm{CH}_{3}$ inplane bending vibration occurred at $1410 \mathrm{~cm}^{-1}$ in FT-IR spectrum. with the experimental values. The $\mathrm{CH}_{3}$ symmetric bending mode observed at $1379 \mathrm{~cm}^{-1}$ in FT-IR value are good agreement with theoretical values $\left(1396\right.$ and $1393 \mathrm{~cm}^{-1}$ the interaction with skeletal stretching modes. Generally, the in-plane and out-of-plane rocking modes observed in the region $1120-1050 \mathrm{~cm}^{-1}$ and $900-800 \mathrm{~cm}^{-1}[30,31]$. In the present molecule, the FT-Raman spectra shows the band at $1112 \mathrm{~cm}^{-1}$ assigned to in-plane rocking and $826 \mathrm{~cm}^{-1}$ in FT-IR spectra are assigned to $\mathrm{CH}_{3}$ out-of-plane rocking mode. As $\mathrm{CH}_{3}$ twisting mode is expected below $400 \mathrm{~cm}^{-1}$, the theoretically computed values are at 236, 182, 234 and $180 \mathrm{~cm}^{-1}$ in B3LYP and methods are assigned to mode, for, no spectral measurements were possible in the region due to instrumental limits. The $\mathrm{C}-\mathrm{CH}_{3}$ stretching vibration observed at $1006 \mathrm{~cm}^{-1}$ FT-Raman spectra and $\mathrm{C}-\mathrm{CH}_{3}$ in-plane and out-of-plane bending vibrations are observed at 573 and 257 $\mathrm{cm}^{-1}$ in FT-IR and FT-Raman spectrum, respectively.

\subsection{Mulliken population analysis}

The natural population analysis of DCPI obtained by Mulliken [33] population analysis with B3LYP level using different basis sets. Mulliken population analysis graph of DCPI are shown in Fig. 6. Mulliken atomic charge calculation has an important role in the application of quantum chemical calculation to molecular system because of atomic charge effect, dipole moment, molecular polarizability, electronic structure and a lot of properties of molecular systems. Mulliken atomic charges calculated at the B3LYP method with 6-31+G (d) and 6-311++G (d, p) basis sets are collected in Table4. It is worthy to mention that $\mathrm{C}_{2}$, $\mathrm{C}_{5}, \mathrm{C}_{8}, \mathrm{Cl}_{10}, \mathrm{H}_{11}, \mathrm{H}_{12}, \mathrm{Cl}_{13}$ and $\mathrm{H}_{14}$ atoms of DCPI exhibit positive charge, while $\mathrm{C}_{1}, \mathrm{C}_{3}, \mathrm{C}_{4}, \mathrm{C}_{6}, \mathrm{~N}_{7}$ and $\mathrm{O}_{9}$ atoms exhibit negative charges. The maximum negative charge values of about -0.90251 in $\mathrm{C}_{1}$ atom and $\mathrm{C}_{2}$ has a maximum positive charge values of about 0.86181 in the molecule at B3LYP/6-31+G (d) and B3LYP/6-311++G (d, p) level of theory. 


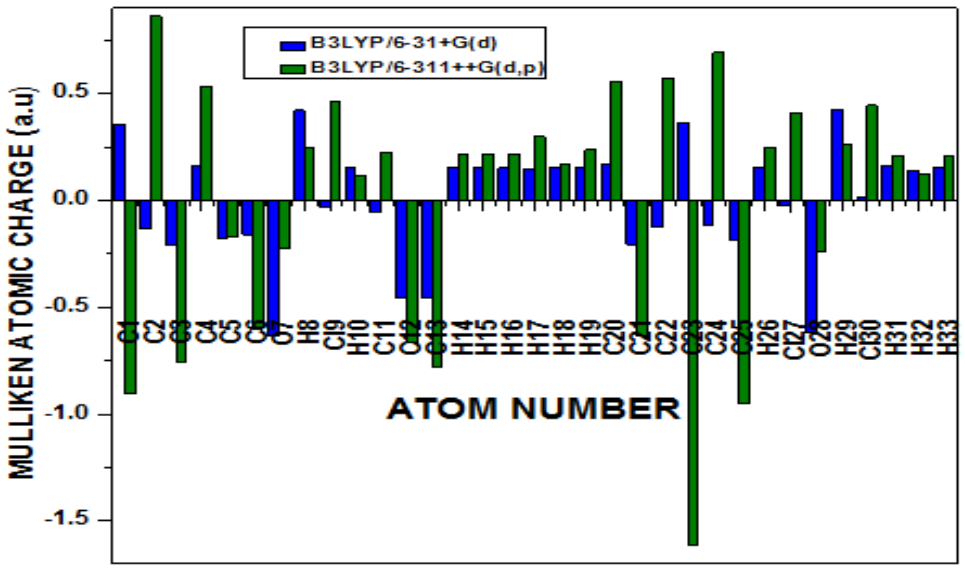

Fig. 6. Comparative Mulliken's plot by B3LYP/6-31+G (d) and B3LYP/6-311++G (d, p) Level 4, 4-isopropylidenebis (2,6 dichlorophenol)

Tabe 4. Mulliken's popuation anaysis of 4,4-isopropylidenebis (2,6-dichlorophenol) at B31YP/6-31+G (d) and B3LYP/6-311++G (d, p)

\begin{tabular}{|c|c|c|c|}
\hline S. No. & Atom No. & \multicolumn{2}{|c|}{ Mulliken's Atomic charges } \\
\hline 3 & $\mathrm{C}_{3}$ & -0.2083 & -0.6234 \\
\hline 4 & $\mathrm{C}_{4}$ & 0.1614 & 0.3272 \\
\hline 5 & $\mathrm{C}_{5}$ & -0.1805 & -0.5417 \\
\hline 8 & $\mathrm{H}_{8}$ & 0.4219 & 0.2539 \\
\hline 9 & $\mathrm{Cl}_{9}$ & -0.0327 & 0.4533 \\
\hline 10 & $\mathrm{H}_{10}$ & 0.1524 & 0.1732 \\
\hline 11 & $\mathrm{C}_{11}$ & -0.0553 & 0.0237 \\
\hline 12 & $\mathrm{C}_{12}$ & -0.4585 & -0.5502 \\
\hline 13 & $\mathrm{C}_{13}$ & -0.4585 & -0.5222 \\
\hline 18 & $\mathrm{H}_{18}$ & 0.1578 & 0.1766 \\
\hline 19 & $\mathrm{C}_{19}$ & 0.1543 & 0.1544 \\
\hline 20 & $\mathrm{C}_{20}$ & 0.1680 & -0.1518 \\
\hline 21 & $\mathrm{C}_{21}$ & -0.2071 & -0.5278 \\
\hline 22 & $\mathrm{C}_{22}$ & -0.1242 & 0.9938 \\
\hline 23 & $\mathrm{C}_{23}$ & 0.3626 & -1.5504 \\
\hline 24 & $\mathrm{C}_{24}$ & -0.1163 & 0.8429 \\
\hline 25 & $\mathrm{C}_{25}$ & -0.1860 & -0.9605 \\
\hline 26 & $\mathrm{H}_{26}$ & 0.1557 & 0.1772 \\
\hline 27 & $\mathrm{Cl}_{27}$ & -0.0235 & 0.4507 \\
\hline 28 & $\mathrm{O}_{28}$ & -0.6178 & -0.1180 \\
\hline
\end{tabular}

methods.

\subsection{Molecular electrostatic potentials (MEP)}


Molecular electrostatic used extensively for interpreting potentials have been and predicting the reactive behavior of a wide variety of chemical system in both electrophilic and nucleophilic reactions, the study of biological recognition processes and hydrogen bonding interactions [32]. $\mathrm{V}(\mathrm{r})$, at a given point $\mathrm{r}(\mathrm{x}, \mathrm{y}, \mathrm{z})$ in the vicinity of a compound, is defined in terms of the interaction energy between the electrical charge generated from the compound electrons and nuclei and positive test charge (a proton) located at $\mathrm{r}$. Unlike, many of the other quantities used at present, and earlier as indices of reactivity $\mathrm{V}(\mathrm{r})$ is a real physical property that can be determined experimentally by diffraction or by computational methods. For the systems studied the molecular electrostatic potential values were calculated as described previously, using the equation [33].

$$
\mathrm{V}(\mathrm{r})=\sum \frac{Z_{A}}{\left|R_{A}-r\right|}-\int \frac{\rho\left(r^{\prime}\right)}{\left|r^{\prime}-r\right|} d r
$$

where the summation runs over all the nuclei $A$ in the compound and polarization and reorganization effects are neglected. $Z_{A}$ is the charge of the nucleus $A$, located at $R_{A}$ and $\rho\left(r^{\prime}\right)$ is the electron density function of the molecule.

To predict reactive sites for electrophilic and nucleophilic attack for the investigated compound, molecular electrostatic potential (MEP) was calculated at B3LYP/6-311++G $(\mathrm{d}, \mathrm{p})$ optimized geometries. The different values of the electrostatic potential at the surface are represented by different colors; red represents regions of most electro negative electrostatic potential, blue represents regions of the most positive electrostatic potential and green represents region of zero potential. Potential decreases in the order red < orange < yellow < green < blue. The MEP surface provides necessary information about the reactive sites. The electron total density onto which the electrostatic potential surface has been mapped is shown in Fig.7. The negative regions $\mathrm{V}(\mathrm{r})$ were related to electrophilic reactivity and the positive ones to nucleophilic reactivity. As easily can be seen in Fig.7, this figure provides a visual representation of the chemically active sites and comparative reactivity of atoms [34].

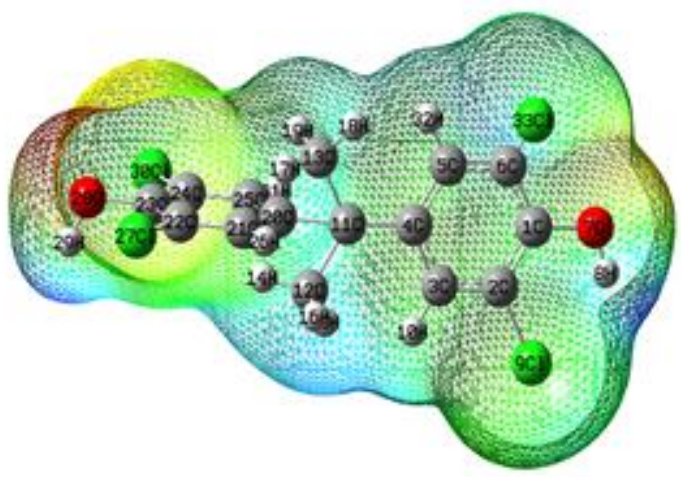

Fig. 7. Calculated 3D molecular electrostatic potential contour map of 4,4- isopropylidenebis (2,6-dichlorophenol)

\subsection{Frontier molecular orbital's (FMOs)}

The most important orbital's in molecule is the frontier molecular orbital's, called highest occupied molecular orbital (HOMO) and lowest unoccupied molecular orbital (LUMO). These orbitals determine the way of molecule interacts with other species. The frontier molecular energy gap helps to characterize the chemical reactivity and kinetic stability of the molecule. A molecule with a small frontier orbital gap is more polarizable and is generally associated with a high chemical reactivity, low kinetic stability and is also termed as soft molecule [35]. The low values of frontier orbital gap in IPDP it more chemical reactive and less kinetic stable. The frontier molecular orbital's plays an important role in the electric and optical properties [36]. The conjugated molecules are characterized by a small highest occupied molecular orbital - lowest unoccupied molecular orbital (HOMO - LUMO) separation, which is the result of a significant degree of intramolecular charge transfer from the endcapping electron acceptor groups through $\pi$ - conjugated path [37]. The 3D plot of the frontier orbital's HOMO and LUMO of DCPI molecule is shown in Fig. 8. The positive phase is red and negative phase one is green (For interpretation of the reference to color in the text, the reader is referred to the web version of the article). Many organic molecules, conjugated $\pi$ electrons are characterized by large values of molecular first hyperpolarizabilities, were analyzed by means of vibrational spectroscopy $[38,39]$. In most cases, even in the absence of inversion symmetry, the strongest band in the FT-Raman spectrum is weak in the FT-IR spectrum vice versa. But the intramolecular charge transfer from the donor-acceptor group in a single - double bond conjugated path can induce large variations of both the dipole moment and the polarizability, making FT-IR and FT-Raman activity strong at the same time. The analysis of wave function indicates that the electron absorption corresponds to the transition from the ground state to the excited state and is mainly described by one. An electron excitatio from the high 
occupied molecular orbital to the lowest unoccupied molecular orbital (HOMO - LUMO) Generally, the energy gap between the HOMO and LUMO decreases, it is easier for the electrons of the HOMO to be excited. The higher energy of HOMO, the easier it is for HOMO to donate electrons whereas it is easier for LUMO to accept electrons when the energy of LUMO is low. The energy values of HOMO and LUMO levels are computed to be -0.20937 a.u. and -0.06573 a.u., respectively, and energy difference is $-12,1888$ a.u. in B3LYP/6-31+G (d). The energy values of HOMO and LUMO levels in B3LYP/6-311++G (d, p) is to be -0.20796 a.u. and -0.06420 a.u. and energy difference is 3.9119 a.u., respectively

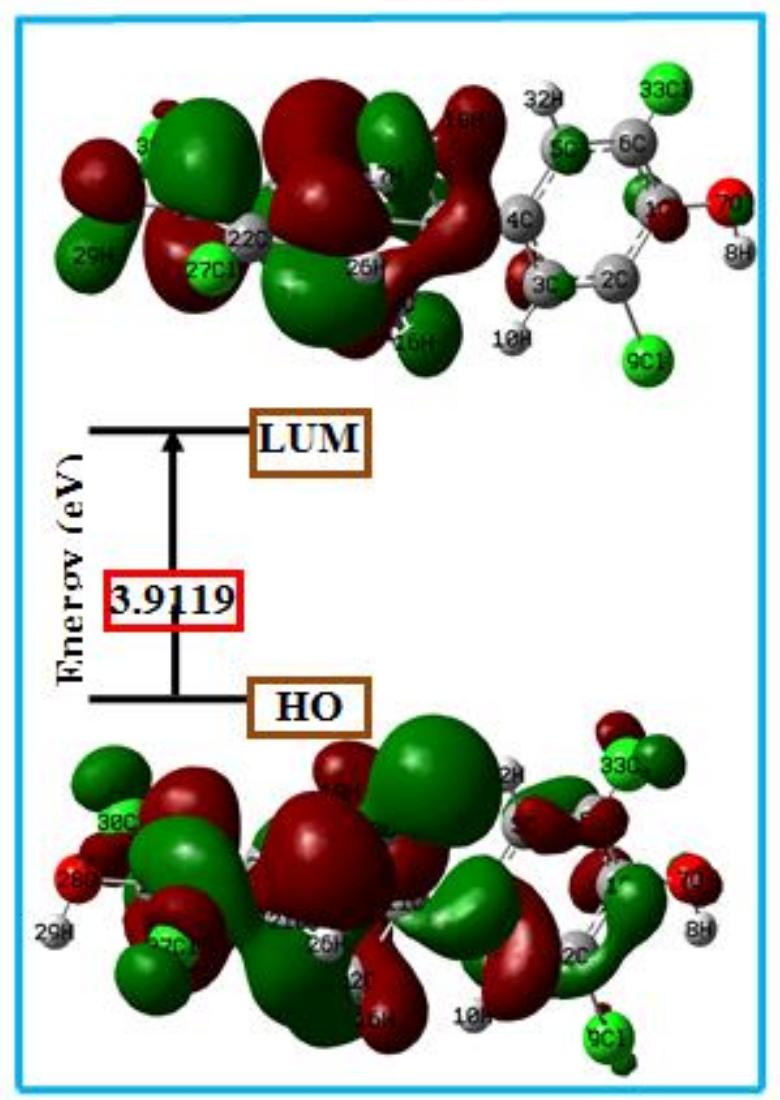

Fig. 8. The molecular orbitals and energies for the HOMO and LUMO of 4,4-isopropylidenebis (2,6-dichlorophenol)

Table 5. Comparison of HOMO, UMO energy gaps and reated moecuar properties of of 4,4-isopropylidenebis (2,6dichlorophenol) at B3LYP/6-31+G (d) and B3LYP/6-311++G (d, p) methods.

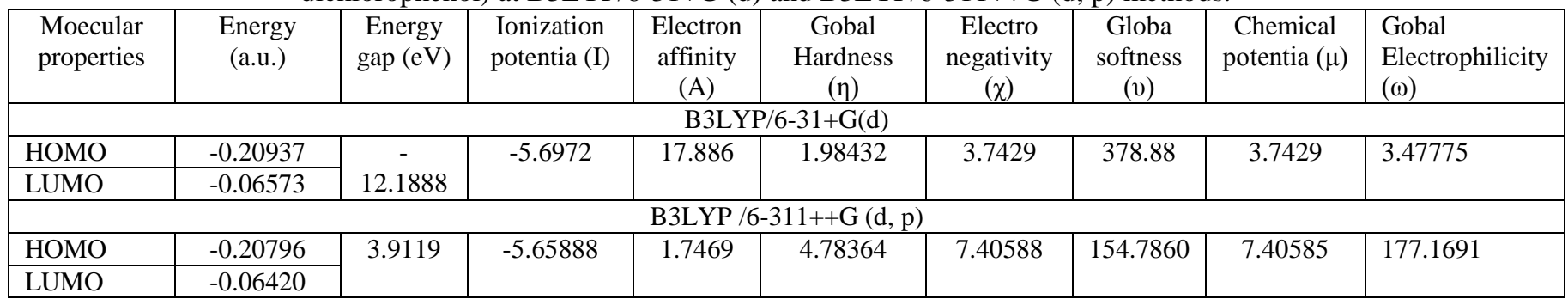

\subsection{Global and local reactivity descriptors}

Based on the density functional descriptors, global chemical reactivity descriptors of title molecule such as global hardness ( $\eta$ ), chemical potential $(\mu)$, global softness $(\sigma)$, electronegativity $(\chi)$, ionization potential $(I)$, electron affinity $(A)$ and global electrophilicity $(\omega)$ as well as local reactivity have been defined [40,41] as follows: 


$$
\begin{aligned}
& \eta=\frac{1}{2}\left(\frac{\partial^{2} E}{\partial N^{2}}\right)_{V(r)}=\frac{1}{2}\left(\frac{\partial \mu}{\partial N}\right)_{V(r)} \\
& \mu=\left(\frac{\partial E}{\partial N}\right)_{V(r)} \\
& \chi=-\mu=-\left(\frac{\partial E}{\partial N}\right)_{V(r)}
\end{aligned}
$$

where $E$ is the total energy, $N$ is the number of electrons of the chemical species, $\eta$ is the chemical potential and $\mathrm{V}(\mathrm{r})$ is the external potential, which is identified as the negative of the electronegativity $(\chi)$ as defined by Iczkowski and Margrave [42]. According to Koopman's theorem [43], the entries of the HOMO and the LUMO orbital's of the molecule are related to the ionization potential $(I)$ and the electron affinity $(A)$, respectively, by the following reactions:

$$
\begin{aligned}
& I=-E_{\text {номо }} \\
& A=-E_{\text {LUMO }}
\end{aligned}
$$

Absolute electronegativity $(\chi)$ and absolute hardness $(\eta)$ of the molecule are given by [59], respectively. Softness $(\sigma)$ is a property of compared the measures the extent of chemical reactivity. It is the reciprocal of hardness.

$$
\begin{aligned}
& \chi=(1+A) / 2 \\
& \eta=(1-A) / 2 \\
& \sigma=\frac{1}{\eta}
\end{aligned}
$$

Recently Parr et al. [44] have defined a new descriptor to quantity of global electrophilic power of the compound as electrophilicity index $(\omega)$ in terms of chemical potential and hardness as follows:

$$
\omega=\left(\frac{\mu^{2}}{2 \eta}\right)
$$

All the calculate values of quantum chemical parameters of the moleculre in both basis sets of DFT are presented in

\section{CONCLUSION}

In the present work, the optimized molecular structure of the stable conformer, vibrational and electronic properties of the title compound have been calculated by DFT method (B3LYP) using 6-31+G (d) basis set. The optimized geometric parameters (bond lengths and bond angles) are theoretically determined and compared with the experimental results. Spectroscopic properties of the present molecule were examined by FT-IR and FT-Raman techniques. The complete vibrational assignments of wavenumbers are made on the basis of potential energy distribution (PED). The electronic properties are also calculated in different solvent with UV-Vis spectrum. The energies of MOs and the $\lambda_{\max }$ of the compound are also evaluated TDDFT/B3LYP method with 6-31+G (d) basis set. The calculated HOMO, LUMO energy and frontier orbital energy gap values along with study for better understanding of charge transfer occur within the molecule.

\section{REFERENCES}

[1] R.N. Griffin, Photochem. Photobiol. 7, 1968, 159-173.

[2] L. Lindqvist, J. Phys. Chem. 76, 1972, 821-822.

[3] X. Zhang, L. Shan, H. Huang, X. Yang, X. Liang, A. Xing, H. Huang, X. Liu, J. Su, W. Zhang, J. Pharm. Biomed. Anal. 49, 2009, 715-725.

[4] Z.B. Liu, Y.S. Sun, J.H. Wang, H.F. Zhu, H.Y. Zhou, J.N. Hu, J. Wang, Sep. Purif. Technol. 64, 2008, $247-252$.

[5] Y.R. Prasad, A.S. Rao, R. Rambabu, Asian J. Chem. 21, 2009, 907-914.

[6] S. Cacchi, G. Fabrizi, F. Gavazza, A. Goggiamani, Org. Lett. 5, 2003, 289-291.

[7] P.M. Sivakumar, G. Sheshayan, M. Doble, Chem. Biol. Drug Des. 72, 2008, 303-313.

[8] H.Z. Wei, L.C. Wing, H.L. Yuan, S.S. Yau, C.L. Yong, H.Y. Chi, Heterocycles, 45, 1997, 71-75.

[9] M.J. Climent, A. Corma, S. Iborra, A. Velty, J. Catal. 221, 2004, 474-482.

[10] H.G. Korth, M.I. de Heer, P. Mulder, J. Phys. Chem. 106, 2002, 8779-8789.

[11] A. Asensio, N. Kobko, J.J. Dannenberg, J. Phys. Chem. A 107, 2003, 6441-6443.

[12] M.J. Frisch, et al., GAUSSIAN 09, Revision A. 9, Gaussian, INC, Pittsburgh, 2009.

[13] H.B. Schlegel, J. Comput. Chem. 3, 1982, 214-218.

[14] E.D. Glendening, A.E. Reed, J.E. Carpenter, F. Weinhold. NBO Version 3.1.TCI. University of Wisconsin, Madison, 1998.

[15] T. Sundius, J. Mol. Struct. 218, 1990, 321-326; MOLVIB: A Program for Harmonic force field calculations. QCPE Program No. 807, 2002. 
[16] P.L. Polavarapu, J. Phys. Chem. 94, 1990, 8106-8112.

[17] G. Keresztury, BT Raman spectroscopy. Theory, in: J.M. Chalmers, P.R. Griffiths (Eds.), Handbook of Vibrational Spectroscopy, Vol. 1, John Wiley \& Sons Ltd., 2002, 71-87.

[18] Uwe Monkowius, Manfred Zabel, Acta Cryst Sec. E 64, 2008, m196.

[19] Min Zhang, Xian-You Yuan, Seik Weng Ng, Acta Cryst. Sec. E 66, 2010, o2917.

[20] E.G. Lewars, computational chemistry, Spriger Science, Business media. B.V., 2011, doi: 10:1007/978-90-481-3862-3-2.

[21] N.P.G. Roges, A Guide to the Complete Interpretation of Infrared Spectra of Organic Structures, Wiley, New York, 1994.

[22] V. Krishnakumar, N. Surumbakuzhali, S. Muthunatesan, Spectrochim. Acta A 71, 2009, 1810-1813.

[23] G. Socrates, Infrared Characteristic Group Frequencies, John Wiley \& Sons, Interscience Publication, New York, Brisbane, Toronto 1980

[24] G. Varsanyi, Assignments for Vibrational Spectra of Seven Hundred Benzene Derivatives, vol. 1/2, Academic Kiado, Budapset, 1973.

[25] S. Gunasekaran, R. ArunBalaji, S. Seshadri, S. Muthu, Indian J. Pure Appl. Phys. 46, 2008, 162-168.

[26] S.Saravanan, V. Balachandran, K. Viswanathan, Spectrochim. Acta part A 121, 2014, 685-697. 